\section{Penelitian Asli}

\section{PERBEDAAN PENGETAHUAN KADER SEBELUM DAN SESUDAH DILAKUKAN TELEEDUKASI MENCUCI TANGAN DI TENGAH WABAH COVID-19 DI KELURAHAN BURANGRANG, BANDUNG}

\author{
Fachreza Aryo Damara, ${ }^{1}$ Fathani Nabila, ${ }^{1}$ \\ Rahmanovarina Nuzulul Rainy, ${ }^{1}$ Sekar Ananggadipa \\ Putri, ${ }^{1}$ Dani Ferdian ${ }^{2}$ \\ 1Program Studi Profesi Dokter, Fakultas Kedokteran, \\ Universitas Padjadjaran, Bandung \\ 2Departemen IImu Kesehatan Masyarakat, Fakultas \\ Kedokteran, Universitas Padjadjaran, Bandung
}

\begin{abstract}
ABSTRAK
Pendahuluan: Upaya pencegahan dan promosi kesehatan merupakan dua hal yang penting dalam membangun kesehatan masyarakat. Di dalam upaya pencegahan dan promosi kesehatan tersebut, kader memiliki peran yang besar. Kader memiliki kesempatan yang lebih besar untuk melakukan edukasi langsung kepada masyarakat. Namun, kegiatan ini menjadi sulit dilakukan sejak dibatasinya pertemuan fisik demi menekan laju penularan di tengah wabah COVID-19. Sehingga langkah teleedukasi yang efektif sangat dibutuhkan terutama mengenai langkah pencegahan utama terhadap penularan COVID-19. Penelitian ini bertujuan untuk mengetahui efek penggunaan teleedukasi melalui Youtube dan Whatsapp untuk meningkatkan pemahaman masyarakat mengenai pencegahan COVID19.

Metode: Penelitian ini merupakan penelitian observasional deskriptif-analitik dengan pendekatan kuantitatif menggunakan metode cross sectional. Subjek penelitian ini merupakan kader Posyandu di wilayah Kelurahan Burangrang, Kecamatan Lengkong, Bandung sebanyak 19 orang.

Hasil: Setelah diberikan teleedukasi, terdapat kenaikan nilai rata-rata post-test yang signifikan yaitu $p=0,000(p<0,001)$. Selain itu juga terdapat peningkatan jumlah impression dan engagement pada video edukasi yang diunggah ke kanal Youtube selama 3×24 jam.

Pembahasan: Di dalam upaya pelaksanaan teleedukasi pada kader Posyandu dengan keterbatasan kontak fisik di tengah wabah COVID-19, media video menjadi bentuk media yang paling diinginkan. Pemberian materi teleedukasi menggunakan video tentang mencuci tangan disertai dengan melakukan uji pengetahuan sebelum dan sesudah pemberian materi mampu meningkatkan pemahaman kader Posyandu mengenai mencuci tangan yang baik dan benar sebagai upaya pencegahan penularan COVID-19.

Simpulan: Teleedukasi menggunakan media video dapat meningkatkan pengetahuan kader di Kelurahan Burangrang mengenai cuci tangan. Media yang digunakan juga mampu menyampaikan materi edukasi dengan baik berdasarkan peningkatan jumlah impression dan engagement pada media.
\end{abstract}

Kata Kunci: COVID-19, Cuci tangan, Edukasi daring, Pengetahuan, Teleedukasi 


\title{
THE DIFFERENCE OF CADRE KNOWLEDGE BEFORE AND AFTER HANDWASHING TELE-EDUCATION IN COVID-19 OUTBREAK AT BURANGRANG VILLAGE, BANDUNG
}

\begin{abstract}
Background: Health prevention and promotion are both important in making better public health. In order to actualize both aspects, Posyandu cadre play major role. Cadre have bigger chance and impact to educate the people who are living around them. However, doing a direct education has become more difficult since physical contacts were minimalized during this COVID-19 outbreak. Therefore, an effective tele-education is needed as an effort to prevent COVID-19 transmission. The study aims to evaluate the effect of tele-education through Youtube and Whatsapp to enhance people's understanding on COVID-19 transmission prevention. Method: The study was a cross-sectional study with observational descriptive-analytical methods and quantitatively approach. Subject of the study was Posyandu cadre in Burangrang Village, Lengkong District, Bandung with total subject was 19. Results: After a tele-education had given, there was an increase in total score mean between pretest and posttest with $p=0.000(p<0.001)$. Moreover, there were increases in both social media's impression and engagement on educational video which was uploaded on Youtube. Discussion: In doing Tele-education to Posyandu cadre, video as a media to deliver the content was more preferred. Sharing the knowledge through video along with evaluating participants' understanding of the given topics could enhance cadre knowledge about handwashing as a prevention in the middle of COVID-19 outbreak. Conclusion: Tele-education using video could enhance cadre's understanding about handwashing. The media that has been used was able to deliver the content based on impression and engagement evaluations.
\end{abstract}

Keywords: COVID-19, Handwashing, Knowledge, Online education, Tele-education

\section{PENDAHULUAN}

Promosi kesehatan adalah

kegiatan yang dilakukan untuk memberdayakan masyarakat dengan cara menginformasikan, memengaruhi, dan membantu masyarakat agar berperan aktif menuju derajat kesehatan yang optimal. Penyelenggaraan promosi kesehatan harus didukung dengan metode dan media yang tepat, data dan informasi yang akurat, serta sumber daya manusia yang profesional. ${ }^{1}$ Promosi kesehatan merupakan salah satu Upaya Kesehatan Masyarakat (UKM) yang bersifat esensial bagi Puskesmas demi tercapainya standar pelayanan minimal. Bentuk kegiatan promosi kesehatan diantaranya adalah penyuluhan, pemberdayaan masyarakat, pelatihan kader, dan advokasi. ${ }^{2}$ Dalam upaya promosi kesehatan, kader memiliki peran yang besar untuk membantu melakukan edukasi kepada masyarakat, sehingga kader harus dibekali pengetahuan yang memadai oleh Puskesmas.
Di tengah pandemi Coronavirus Disease (COVID-19) ini, pencegahan penularan merupakan hal yang penting dilakukan. Tindakan pencegahan penularan salah satunya adalah dengan mencuci tangan secara teratur menggunakan sabun dan air bersih minimal selama 20 detik atau menggunakan hand sanitizer berbasis alkohol $60 \%$ jika tidak tersedia air dan sabun. $^{3-5}$ Diharapkan tim baik dari Puskesmas setempat, kader, dan pihakpihak lain terkait dapat memberikan informasi mengenai pencegahan penularan serta promosi kesehatan untuk masyarakat di lingkungannya. ${ }^{6}$ Upaya promosi kesehatan berupa penyuluhan secara langsung yang tengah digencarkan menjadi terhambat dengan adanya himbauan dari Walikota Bandung untuk menghentikan sementara kegiatan yang melibatkan massa sebagai langkah antisipasi COVID-19.7 Dengan demikian, perlu dikembangkan metode promosi kesehatan lain yang tetap dapat 
membekali pengetahuan kader mengenai pencegahan penularan COVID-19.

Penelitian ini bertujuan untuk mengetahui efek pemberian teleedukasi melalui media Youtube dan Whatsapp terhadap peningkatan pengetahuan kader Posyandu Kelurahan Burangrang terhadap mencuci tangan sebagai upaya pencegahan penularan COVID-19.

\section{METODE}

\subsection{Kriteria Subjek}

penelitian

Desain penelitian ini merupakan observasional dengan penelitian pengambilan sampel merupakan total sampling pada kader Posyandu Kelurahan Burangrang, Kecamatan Lengkong, Bandung melalui grup media sosial Whatsapp.

\subsection{Identifikasi Permasalahan dan Konfirmasi Penyebab Masalah}

Identifikasi permasalahan dilakukan melalui survei secara daring pada kader Posyandu di Kelurahan Burangrang, Bandung. Survei berisi pertanyaan mengenai pengetahuan pencegahan penularan virus COVID-19. Prioritas masalah ditentukan berdasarkan jumlah prevalensi permasalahan tertinggi. Analisis penyebab masalah dilakukan dengan metode Ishikawa atau Fishbone method terhadap analisis masukan (input) dan dilakukan konfirmasi penyebab masalah melalui survei pada pihak Puskesmas, staf promosi kesehatan, dan kader Posyandu.

\subsection{Penyampaian Materi Teleedukasi dan Evaluasi Pengetahuan}

Materi edukasi disiapkan dalam bentuk video yang diunggah ke kanal Youtube. Peserta diberikan pertanyaan pre-test sebelum diberikan materi edukasi. Tautan video diunggah ke dalam formulir daring dan disosialisasikan melalui grup Whatsapp kader Posyandu. Formulir daring secara berurutan memuat tautan video dan pertanyaan post-test. Pertanyaan dibuat untuk mengukur tingkat pengetahuan kader sebelum dan sesudah diberikan materi edukasi. Hasil pre-test dan posttest kemudian dilihat signifikansinya menggunakan analisis statistik. Selain itu, kemampulaksanaan media edukasi diukur dengan jumlah impression dan engagement yang dipantau selama $3 \times 24$ jam. Impression adalah jumlah total berapa kali suatu unggahan dilihat, sementara engagement adalah jumlah total like, comment, share, dan save pada suatu unggahan. ${ }^{8}$

Uji distribusi normalitas data menggunakan Saphiro-Wilk dengan penentuan hipotesis berdasarkan uji paired $t$ test atau uji Wilcoxon apabila distribusi tidak normal. Penentuan nilai alfa adalah 0,05. Analisis statistik dilakukan menggunakan perangkat lunak RStudio ver. 1.2.5033.

\section{HASIL PENELITIAN}

\subsection{Perumusan Masalah dan Penyebab Permasalahan}

Berdasarkan hasil survei permasalahan, empat masalah utama yang didapatkan setelah melakukan survei kepada kader Posyandu di Kelurahan Burangrang adalah ketidaktahuan kader Posyandu mengenai penyebab infeksi COVID-19 $(40,5 \%)$, kurangnya pengetahuan mengenai gejala COVID-19 (52,4\%), kurangnya pengetahuan mengenai mencuci tangan yang tepat $(69,4 \%)$, dan ketidaktahuan kader Posyandu mengenai pusat informasi COVID-19 di Jawa Barat (50\%). Sehingga masalah yang dirumuskan adalah mengenai kurangnya pengetahuan kader Posyandu terhadap mencuci tangan.

Konfirmasi penyebab masalah dilakukan dengan survei daring terhadap pihak Puskesmas, staf promosi kesehatan, dan kader Posyandu. Berdasarkan hasil survei didapatkan penyebab masalah yaitu penyuluhan sebelumnya dilaksanakan bersamaan dengan Posyandu (75\%), penyuluhan cuci tangan dilaksanakan dengan melihat contoh peragaan kemudian memeragakan ulang bersama, namun tidak ada media edukasi yang dibawa pulang $(50 \%)$, serta tidak ada tes atau pertanyaan setelah edukasi diberikan (33\%). 


\subsection{Impression dan Engagement}

Kemampulaksanaan media promosi kesehatan dinilai berdasarkan jumlah impression dan engagement yang dipantau selama $3 \times 24$ jam dan didapatkan hasil jumlah impression sebanyak 131 views dan jumlah engagement sebanyak 17 comments serta 45 likes.

Berdasarkan hasil pemantauan tersebut, dapat disimpulkan bahwa terdapat peningkatan jumlah impression dan engagement pada video edukasi yang diunggah ke kanal Youtube selama $3 \times 24$ jam.

\subsection{Tingkat pengetahuan}

Evaluasi tingkat pengetahuan kegiatan promosi kesehatan ini dilakukan dengan menganalisis hasil pre-test dan post-test. Pre-test dan posttest terdiri dari 10 pertanyaan yang sama, dengan bobot jawaban pertanyaan benar adalah 1 , dan salah adalah 0 . Terdapat 19 responden dari 3 grup Whatsapp yang mengisi pertanyaan pre-test dan post-test.

Setelah dilakukan penilaian terhadap jawaban responden, didapatkan pre-test rata-rata nilai 6,95 $(95 \% \mathrm{Cl} 6,04-7,85)$ dengan nilai terkecil 4 dan nilai tertinggi 10. Pada post-test didapatkan rata-rata nilai $8,23(95 \% \mathrm{Cl}$ $7,64-8,88)$ dengan nilai terkecil 6 dan nilai tertinggi 10 . Berdasarkan penilaian uji Saphiro-Wilk, ditemukan data terdistribusi normal pada kedua nilai pretest dan post-test yang diindikasikan dengan nilai $p>0,05$. Perbedaan rata-rata nilai pre-test dan post-test signifikan berdasarkan hasil uji paired $t$ test, dengan $p=0,000(p<0,001)$.

Dengan demikian, dapat disimpulkan bahwa terdapat kenaikan rata-rata nilai hasil dari pertanyaan pretest dan post-test yang signifikan setelah pemberian materi edukasi.

\section{PEMBahASAN}

Kegiatan penyuluhan bertujuan untuk mengetahui gambaran tingkat pengetahuan masyarakat mengenai langkah mencuci tangan yang tepat sesuai dengan anjuran WHO dalam menghadapi wabah COVID-19 saat ini. Selain untuk mengetahui tingkat pengetahuan masyarakat, penyuluhan juga bertujuan untuk meningkatkan pengetahuan masyarakat. Namun, dengan adanya physical distancing, keterbatasan kontak fisik menjadi tantangan dalam melakukan kegiatan penyuluhan. $9,10 \quad$ Berdasarkan Notoatmodjo, pengetahuan bisa didapatkan dari proses pembelajaran yang dapat menimbulkan keyakinan dan mengubah sikap seseorang dalam mengambil tindakan. ${ }^{11,12}$ Pengetahuan ini dapat dibangun melalui proses pembelajaran berupa pelatihan.

Dalam melakukan pencegahan penularan COVID-19, berbagai hal dapat dilakukan seperti mencuci tangan, melakukan evaluasi gejala diri, etika batuk yang tepat, dan menjaga jarak dengan orang lain. ${ }^{13-15}$ Namun, melakukan identifikasi permasalahan melalui survei menjadi hal penting agar intervensi teleedukasi yang diberikan menjadi tepat sasaran. Subjek teleedukasi juga memegang peranan penting untuk mencapai tingkat pengetahuan yang baik pada masyarakat. Kader Posyandu memiliki peran besar dan kesempatan yang banyak dalam bertemu masyarakat seiring dengan fasilitas layanan kesehatan primer. ${ }^{16}$ Sehingga, melakukan teleedukasi kepada kader Posyandu dapat memberikan luaran yang baik terhadap peningkatan pengetahuan masyarakat.

Dengan keterbatasan kontak fisik ditengah wabah COVID-19, penggunaan media daring menjadi langkah utama dalam melakukan penyampaian informasi kepada masyarakat. Terdapat berbagai jenis media yang dapat digunakan, diantaranya media visual seperti e-poster atau e-leaflet, audio seperti podcast maupun audio visual seperti video. Dengan mengoptimalkan masukan informasi yang akan diterima oleh masyarakat, penggunaan video dinilai lebih efektif. ${ }^{17}$ Selain itu, jalur informasi yang digunakan untuk menyebarluaskan informasi materi edukasi juga berperan penting. Survei global terhadap penggunaan platform media sosial menunjukkan mayoritas masyarakat Indonesia menggunakan media sosial 
Youtube dan Whatsapp. ${ }^{18}$ Sehingga, penyebarluasan materi edukasi dapat dilakukan dengan pengunggahan video pada media sosial tersebut.

Berdasarkan evaluasi kegiatan promosi kesehatan yang telah dilaksanakan, saran yang penulis harapkan agar upaya dapat dilakukan secara tindak lanjut, adalah: 1) media edukasi daring dapat menjadi salah satu pilihan promosi kesehatan yang secara terukur dapat meningkatkan pengetahuan sasaran, sehingga waktu dan ruang tidak lagi menjadi keterbatasan bagi pihak-pihak terkait untuk memberikan edukasi; 2) selain melalui teleedukasi dengan platform Whatsapp dan video yang diunggah ke kanal Youtube, perlu dikembangkan metode edukasi lain yang lebih meningkatkan partisipasi sasaran sehingga tercapai efektivitas edukasi 2 arah secara maksimal; 3) evaluasi secara jangka panjang dapat dilakukan untuk memastikan pemahaman yang dimiliki oleh kader Posyandu dan masyarakat semakin baik.

\section{SIMPULAN}

Teleedukasi menggunakan media video dapat meningkatkan pengetahuan kader di Kelurahan Burangrang mengenai cuci tangan. Media yang digunakan juga mampu menyampaikan materi edukasi dengan baik berdasarkan peningkatan jumlah impression dan engagement pada media

\section{UCAPAN TERIMAKASIH}

Ucapan terimakasih penulis ucapkan kepada dr. Liawaty Tarigan, SpDLP yang telah membantu dalam proses pengambilan data.

\section{DAFTAR PUSTAKA}

1. Kementrian Kesehatan Republik Indonesia. Peraturan Menteri Kesehatan Republik Indonesia Nomor 74 Tahun 2015 Tentang Upaya Peningkatan dan Pencegahan Penyakit. Jakarta; 2015.

2. Kementrian Kesehatan Republik Indonesia. Peraturan Menteri Kesehatan Republik Indonesia Nomor 75 Tahun 2014 Tentang
Pusat Kesehatan Masyarakat. Jakarta; 2014.

3. Desai AN, Patel P. Stopping the Spread of COVID-19. JAMA. 2020 Mar 20

4. Singhal T. A Review of Coronavirus Disease-2019 (COVID-19). Vol. 87, Indian Journal of Pediatrics. Springer; 2020. p. 281-6.

5. World Health Organization. Household transmission investigation protocol for coronavirus disease 2019 (COVID-19). 2020

6. Kementrian Kesehatan Republik Indonesia. Pedoman Pencegahan dan Pengendalian Coronavirus Disease (COVID19). 2020;3:1-116.

7. Dinas Kesehatan Kota Bandung. Surat Edaran Walikota Bandung Nomor 443/SE.030-Dinkes. Bandung, Indonesia; 2020.

8. Freberg K. Social Media for Strategic Communication. 2018.

9. A W-S, D F. Isolation, quarantine, social distancing and community containment: pivotal role for oldstyle public health measures in the novel coronavirus (2019nCoV) outbreak. Journal Travel Med. 2020 Mar;27(2).

10. Anderson $\mathrm{RM}$, Heesterbeek $\mathrm{H}$, Klinkenberg D, Hollingsworth TD. How will country-based mitigation measures influence the course of the COVID-19 epidemic? Vol. 395, The Lancet. Lancet Publishing Group; 2020. p. 9314.

11. Notoatmodjo S. Pendidikan dan Perilaku Kesehatan. Jakarta: Rhineka Cipta; 2003.

12. Notoatmodjo S. Ilmu Perilaku Kesehatan. Jakarta: Rhineka Cipta; 2010.

13. Wu Z, McGoogan JM. Characteristics of and Important Lessons from the Coronavirus Disease 2019 (COVID-19) Outbreak in China: Summary of a Report of 72314 Cases from the Chinese Center for Disease Control and Prevention. JAMA - J Am Med Assoc. 2020; 
14. Lauer SA, Grantz KH, Bi Q, Jones FK, Zheng Q, Meredith HR, et al. The Incubation Period of Coronavirus Disease 2019 (COVID-19) From Publicly Reported Confirmed Cases: Estimation and Application. Ann Intern Med. 2020 Mar 10

15. Rothan HA, Byrareddy SN. The epidemiology and pathogenesis of coronavirus disease (COVID19) outbreak. Journal of Autoimmunity. Academic Press; 2020. p. 102433.

16. Widarti W, Rinawan FR, Susanti Al, Fitri HN. Perbedaan Pengetahuan Kader Posyandu Sebelum dan Sesudah Dilakukan Pelatihan Penggunaan Aplikasi iPOSYANDU. J Pengabdi dan Pengemb Masy. 2019 Feb 8;1(2):143.

17. Roter DL, Larson S, Shinitzky H, Chernoff R, Serwint JR, Adamo $\mathrm{G}$, et al. Use of an innovative video feedback technique to enhance communication skills training. Med Educ. 2004 Feb 1;38(2):145-57.

18. Datareportal. Digital 2020: Indonesia - DataReportal Global Digital Insights [Internet]. [cited 2020 Apr 6]. Available from: https://datareportal.com/reports/d igital-2020-indonesia 